\title{
THE EFFECT OF MIXED BIOLOGICAL PRETREATMENT AND PEG 4000 ON REDUCING SUGAR PRODUCTION FROM COFFEE PULP WASTE
}

\author{
Toto Iswanto ${ }^{1}$, Nuniek Hendrianie ${ }^{1}$, Maya Shovitri ${ }^{2}$, Ali Altway ${ }^{1}$, Tri Widjaja ${ }^{1 *}$ \\ ${ }^{1}$ Department of Chemical Engineering, Institut Teknologi Sepuluh Nopember, Sukolilo, Surabaya \\ 60111 Indonesia \\ ${ }^{2}$ Department of Biology, Institut Teknologi Sepuluh Nopember, Sukolilo, Surabaya 60111, Indonesia
}

(Received: July 2018 / Revised: October 2018 / Accepted: April 2019)

\begin{abstract}
Biological methods using bacteria and fungi are regarded as more economically viable and environmentally friendly alternatives for improving lignocellulosic degradation. Coffee pulp waste $(\mathrm{CPW})$ as a lignocellulosic biomass is abundant and has potential as a reducing sugar feedstock. However, it contains lignin as a matrix polymer, which associated with pectin and cover the cellulosic microfibrils and make it difficult to be digested during the bioprocess. In this study, the performance of biological pretreatment in reducing lignin and pectin using a coculture of Bacillus subtilis (BS), Aspergillus niger (AN), or Trichoderma reesei (TR) has been investigated. The pretreatment of the $\mathrm{CPW}$ was made using various microbial ratios in an aerobic stirred-bioreactor and incubated at $30^{\circ} \mathrm{C}, \mathrm{pH} 5$ for 7 days. Removal of lignin and pectin was analyzed during the pretreatment process. PEG 4000 as a surfactant was used and its effect on the yield of reducing sugar production from pretreated CPW using a A. niger and T. viride (TV) co-culture with a surfactant to substrate ratio of 1:1 (w/w) was investigated. A culture without surfactant was used as a control. The results reveal that the best lignin and pectin removal was $99.9 \%$, when using a co-culture of AN and TR with a ratio of $1: 1(\mathrm{v} / \mathrm{v})$ and of BS and TR with a ratio of $2: 1(\mathrm{v} / \mathrm{v})$. The cellulose content of CPW in these co-cultures was $86.99 \%$ $(\mathrm{w} / \mathrm{w})$ and $81.61 \%(\mathrm{w} / \mathrm{w})$, respectively, and the reducing sugar concentration obtained was 12.5 $\mathrm{g} / \mathrm{L}$ and $9.74 \mathrm{~g} / \mathrm{L}$ respectively. In further hydrolysis of pretreated CPW using a AN:TV (2:1) coculture with the addition of surfactant, the yield of reducing sugar obtained was higher than that of the control, at $20.69 \%$. Use of PEG 4000 as a surfactant had a positive effect on enhancing the yield of reducing sugar from coffee pulp waste.
\end{abstract}

Keywords: Biological pretreatment; Coffee pulp waste; Hydrolysis; Reducing sugar; Surfactant

\section{INTRODUCTION}

The utilization of agro-industrial residues as lignocellulosic biomass to produce more valuable material has encouraged the improvement of advanced biotechnological innovations, principally in enzyme and fermentation technology, which have ultimately had an impact on the reduction of environmental pollution problems (Pandey et al., 2000). One of the agro-industrial residues that is available in abundance in Indonesia, but which has particular problems associated with its utilization due to the presence of anti-nutritional factors such as caffeine,

\footnotetext{
*Corresponding author's email: triw@chem-eng.its.ac.id, Tel. +62-31-5946240, Fax.+62-31-5999282 Permalink/DOI: https://doi.org/10.14716/ijtech.v10i3.2900
} 
tannin, and polyphenols, is coffee pulp waste (CPW). Coffee is an important plantation commodity in Indonesia (Haryuni et al., 2019); the country produces an average amount of $686 \times 10^{6} \mathrm{~kg}$ of coffee each year (Widjaja et al., 2017a). Without proper handling, the abundant untreated CPW will release xenobiotics as toxic substances into the soil, which kill the saprophytic microorganisms, causing disruption to important biotransformation stability in the environment (Ibrahim et al., 2014).

In the biotechnological approach, CPW can be converted into reducing sugar as a substrate to produce biofuels such as ethanol and biogas. To obtain the optimum yield of reducing sugar, a pretreatment process is needed to remove the unnecessary matrix polymers such as lignin and pectin surrounding the cellulosic microfibrils. Pectin is a heterogeneous polysaccharide, whose molecular structure, weight and functional properties depend on its agro-waste source (Kusrini et al., 2018). Pectin has the function of cross-linking cellulose and hemicellulose fibers, providing rigidity to the cell wall (Abbott \& Boraston, 2008). This is in line with Menon and Rao (2012), who state that hemicelluloses, amorphous polymers of different sugars, and other polymers such as pectin, attach the microfibrils of cellulose, which are stabilized by hydrogen bonds and covered by lignin, making the biomass difficult to be digested in the bioprocess.

Physicochemical pretreatment methods have been widely developed, such as steam explosion (Guo et al., 2011), or use of dilute acid (Dussán et al., 2014), alkali (Menezes et al., 2014) or oxidation, or varied combinations of these, but such processes usually involve high temperature, pressure and cost (Kumar et al., 2009). Since chemical or physical methods are not able to provide selective removal, are expensive, and are not environmentally friendly, microbial and enzymatic techniques for lignin and pectin removal could be alternative advantageous methods.

The co-culture strategy has been assessed as a more efficient way to treat lignocellulosic waste (Menon \& Rao, 2012). The combination of cultures can consist of two, three, or a consortium of bacteria or fungi or a mixture of them, which can be applied in many biological production processes. In the case of lignin and pectin removal, previous studies have reported that $A$. niger and T. reesei are capable of degrading lignin (Adav \& Sze, 2014; Asses et al., 2018). Moreover, Roussos et al. (1995) found that some strains of $A$. niger are capable of degrading caffeine. $B$. subtilis can degrade lignin and pectin (Gummadi \& Kumar, 2005; Torimiro \& Okonji, 2013; Cragg et al. 2015). Juliastuti et al. (2018) successfully achieved the combination of three strains, A. niger, Pseudomonas putida, and T. harzianum to treat coffee pulp in degrading lignin and anti-nutritional factor for a biogas feedstock.

Besides applying the pretreatment, the use of surfactants (i.e. PEG 4000) in the hydrolysis of lignocellulosic substrates has produced good effects. Surfactants, as surface-active additives, affect the interaction between enzymes such as cellulase and substrates ( $\mathrm{Li}$ et al., 2012), leading to an increase in the total amount of reducing sugar after the hydrolysis process. PEG is presented in varying molecular weights (e.g. PEG 4000, 6000 and 8000); at the lowest molecular weight (PEG 4000) the amounts of reducing sugar produced were $7 \%$ and $13 \%$ higher than those from PEG 6000 and 8000 respectively (Ivetić et al., 2014). However, the effects of the addition of the same surfactants on the obtained hydrolysis product may be different, depending on the operating conditions, initial chemical content in the substrate, and treatment method during the hydrolysis process.

Therefore, this study conducts an investigation to determine the best co-culture ratio involving $A$. niger, $T$. reesei and $B$. subtilis to develop a co-culture for degrading lignin and pectin at a faster degradation rate and which is able to tolerate the presence of the anti-nutritional factors that effect their growth. The obtained CPW from the best pretreatment condition was further hydrolyzed using a co-culture of $A$. niger and $T$. viride with the addition of PEG 4000. The 
effects of the co-culture on the reducing sugar obtained from the hydrolysis process were also investigated and described.

\section{METHODS}

\subsection{Coffee Pulp Waste Sample}

CPW was collected from Malang, East Java, Indonesia and sun-dried for several days until its weight loss was around 50\%. The size of the dried CPW was reduced to 100 mesh using a disc mill machine. It was then further dried using an oven at $60^{\circ} \mathrm{C}$ for $4 \mathrm{~h}$ to optimally reduce the moisture content. The initial organic compounds of the CPW were analyzed, including cellulose $(57.9 \%)$, hemicelluloses $(21.63 \%)$, lignin $(5.21 \%)$, pectin $(2.28 \%)$, tannin $(4.81 \%)$, polyphenol $(3.48 \%)$, caffeine $(1.58 \%)$ and glucose $(3.11 \%)$.

\subsection{Inoculum Preparation}

A. niger, T. reesei, $T$. viride and B. subtilis were obtained from the stock culture of the Microbiology Laboratory of the Department of Chemical Engineering, Institut Teknologi Sepuluh Nopember, Indonesia, and maintained on a potato dextrose agar (PDA) medium in the case of AN, TR, and TV, and on a nutrient agar (NA) medium for BS. The cultures, which had regrown for 4 days on their fresh media, were inoculated into tubes containing $10 \mathrm{ml}$ of sterilized identical broth with the initial medium. They were then vortexed to obtain a homogeneous suspension. The conidial and cell number in the suspension was estimated by microscopic determination using a counting chamber, as described in the study of Widjaja et al. (2017b).

\subsection{Pretreatment Procedure}

The initial microbe concentration in single culture suspension of B. subtilis, A. niger and T. reesei was $1.15 \times 10^{6}$ cell $/ \mathrm{ml}, 2.45 \times 10^{6}$ conidia $/ \mathrm{ml}$, and $1.65 \times 10^{6}$ conidia/ml, respectively. The cultures were mixed following the mixture ratios shown in Table 1 . Thirty milliliters of coculture inoculum was introduced into an aerobic stirred-bioreactor containing $100 \mathrm{~g}$ of soluted $\mathrm{CPW}$ in $400 \mathrm{ml}$ of water and incubated at $30^{\circ} \mathrm{C}$ for 7 days $(168 \mathrm{~h})$ with agitation of $30 \mathrm{rpm}$. The bioreactor was equipped with a water bath to control the temperature. The initial $\mathrm{pH}$ was 5 . There was no addition of any nutrient or mineral salt to the cultures in order to increase their adaptability to native CPW conditions in the environment.

Table 1 Single culture mixture ratio in the co-culture inoculum

\begin{tabular}{llll}
\hline \multicolumn{1}{c}{ Co-culture inoculum } & \multicolumn{3}{l}{ Mixture ratio (v/v) } \\
\hline B. subtilis : A. niger $(\mathrm{BS}: \mathrm{AN})$ & $1: 1$ & $1: 2$ & $2: 1$ \\
B. subtilis $:$ T. reesei $(\mathrm{BS}: \mathrm{TR})$ & $1: 1$ & $1: 2$ & $2: 1$ \\
A. niger $:$ T. reesei $(\mathrm{AN}: \mathrm{TR})$ & $1: 1$ & $1: 2$ & $2: 1$ \\
\hline
\end{tabular}

\subsection{Reducing Sugar Production from Pretreated CPW}

The various ratios of $A$. niger and $T$. viride were determined at 1:1, 1:2 and 2:1 (v/v). Hydrolysis was performed by weighing $1 \mathrm{~g}$ of the solid sample of pretreated CPW and introducing it into $250 \mathrm{ml}$ Erlenmeyer flasks. $3 \mathrm{ml}$ of co-culture was then inoculated into the flask with the detailed ratios listed in Table 2. Citrate buffer $0.1 \mathrm{M}(\mathrm{pH} 5)$ was then added into the culture until the total volume reached the $30 \mathrm{ml}$ mark. Subsequently, the flasks were incubated in an incubator with an orbital shaker at $30^{\circ} \mathrm{C}$ and $120 \mathrm{rpm}$ for $16 \mathrm{~h}$. The PEG 4000 was added to the culture at a ratio of $1: 1(\mathrm{~g} / \mathrm{g}$ CPW) and a culture without PEG 4000 was used as a control. 


\subsection{Analytical Methods}

During the pretreatment process, a sample from each culture was drawn every 24 hours to determine the solid fraction composition of the lignin and pectin content and the liquid fraction concentration of the reducing sugar. The residual lignin, cellulose and hemicellulose in the solid sample were analyzed using the gravimetric method, following Juliastuti et al. (2017). The pectin content was extracted and analyzed using colorimetric determination by the carbazole method, which was measured using a spectrophotometer at $520 \mathrm{~nm}$, as described by Ranganna (1979). The reducing sugar concentration was measured using the 3,5-dinitrosalicylic acid $\left(\mathrm{C}_{7} \mathrm{H}_{4} \mathrm{~N}_{2} \mathrm{O}_{7}\right)$ method and read at $540 \mathrm{~nm}$. HPLC analysis was only conducted for the reducing sugar concentration obtained from the best co-culture in the pretreatment process.

The reducing sugar yield was measured from the obtained reducing sugar in the hydrolysis process using A. niger and T. viride, as calculated using Equation 1:

Reducing sugar yield $(\%)=$ concentration of reducing sugar $(\mathrm{g} / \mathrm{L}) \times$ vol. of hydrolysate $\times 100$

initial mass of cellulose and hemicellulose

\section{RESULTS AND DISCUSSION}

\subsection{Residual Lignin and Pectin in the Pretreated CPW}

Lignocellulosic biomass pretreatment was needed because it could damage the lignin structure and provide more accessible cellulose during the hydrolysis process due to the increase in material porosity (Sun \& Cheng, 2002; Mood et al., 2013). The reduction in lignin and pectin levels during pretreatment using the co-culture of $B$. subtilis, A. niger and T. reesei can be seen in Figures $1 \mathrm{a}$ and $1 \mathrm{~b}$. The figures show that lignin and pectin content decreased significantly after $24 \mathrm{~h}$ in all the co-cultures, with different degradation rates. However, after $48 \mathrm{~h}$ the degradation of lignin and pectin at CPW decreased slowly. This was probably caused by the microorganisms having attained the stationary phase (data not shown), which eventually leads to a decrease in degradation activity. Growth and enzyme activity were affected by the media conditions, including temperature and $\mathrm{pH}$ (Sohail et al., 2009).

\subsubsection{Co-culture performance on lignin removal}

As shown in Figure 1a, the initial lignin content in the CPW was 5.21\%, which decreased to $0.039 \%, 0.0281 \%$ and $0.025 \%$ in the B. subtilis and A. niger co-culture with ratios of $1: 1,1: 2$, and $2: 1$, respectively. The lignin content then slowly decreased to $0.0045 \%, 0.0045 \%$ and $0.004 \%$ after $168 \mathrm{~h}$ in respect of the same culture ratios. In this co-culture, the best lignin removal was from the $2: 1(\mathrm{v} / \mathrm{v})$ ration. In the $B$. subtilis and $T$. reesei co-culture, lignin significantly decreased after $24 \mathrm{~h}$ of pretreatment time. The lignin contents in the BS:TR (1:1), BS:TR (1:2), and BS:TR (2:1) co-culture were $0.038 \%, 0.023 \%$ and $0.015 \%$, respectively. At the end of the pretreatment, the lignin content of the coffee pulp in the BS:TR $(2: 1)$ co-culture was $0.001 \%$ and was deemed to be the best lignin removal.

The results of these co-cultures reveal that the addition of a higher ratio of $B$. subtilis was able to enhance lignin removal. This was probably caused by B. subtilis, which can effectively degrade lignin by its enzyme. This result is in line with the study of Cragg et al. (2015), which found that $B$. subtilis could degrade the main components of lignin and biphenyl, by $10 \%$. In the previous study, Bacillus sp. strain LD003, isolated from soil on the top of decayed pieces of wood, was reported to be a promising source of novel ligninolytic enzymes, which play an important role during the lignin degradation process (Bandounas et al., 2011). It was also able to grow on the specific medium of lignin monomers, such as phenol, 4-hydroxybenzaldehyde, 4-hydroxybenzoic acid, vanillin, vanillic acid, and syringic acid, as the sole carbon and energy source, leading to a good capacity for selective degradation. Bacillus sp. (accession no. 
EU978470) has also been reported to be able to utilize lignin as a sole carbon source, with maximum lignin degradation of up to $81.4 \%$ at pH 6 for 6 days (Abd-Elsalam \& El-Hanafy, 2009). Bacillus sp. strains CS-1 and CS-2 isolated from forest soils in Japan have been investigated by Chang et al. (2014), and were shown to be able to degrade $61 \%$ of alkali lignin within $48 \mathrm{~h}$ with initial lignin of $0.05-2.0 \mathrm{~g} / \mathrm{L}$. The degradation was correlated with laccase activities, observed in its crude enzyme extracts.

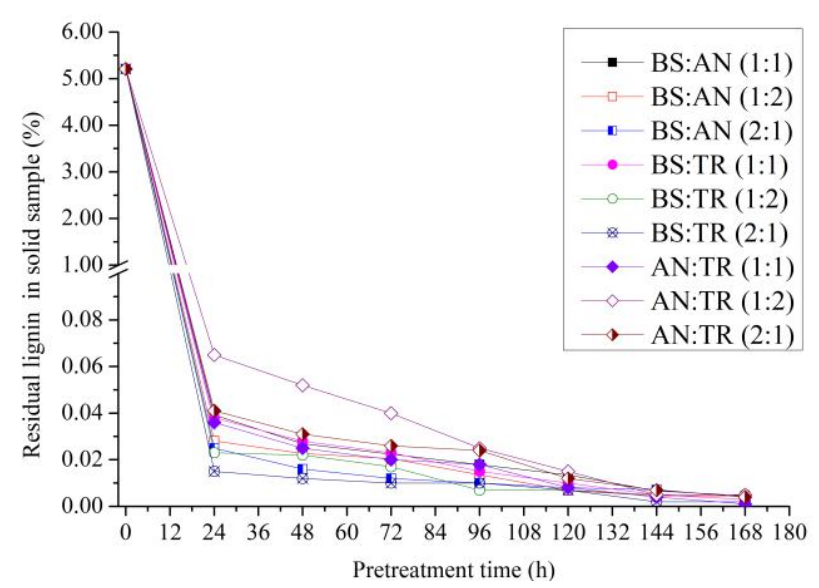

(a)

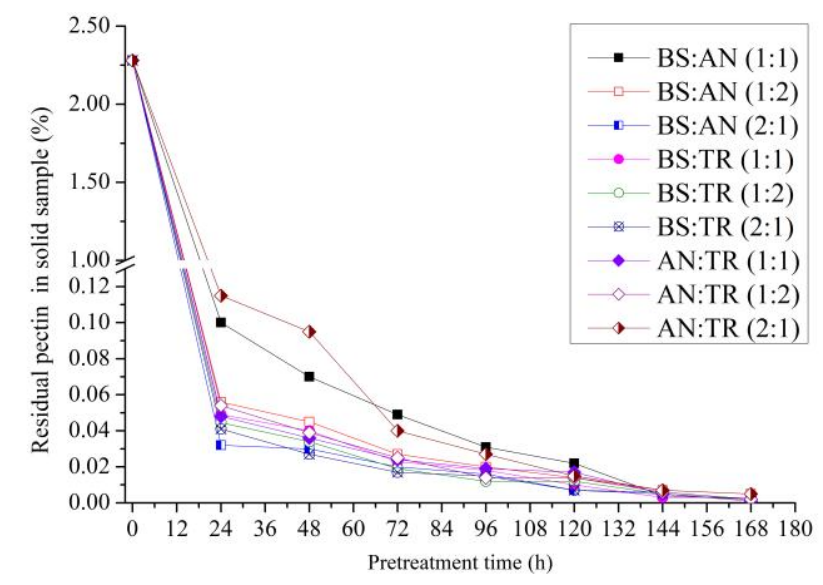

(b)

Figure 1 Residual lignin and pectin in the solid sample of pretreated CPW: (a) lignin; (b) pectin

A significant decrease in lignin after $24 \mathrm{~h}$ also occurred in the A. niger and T. reesei co-culture, to levels of $0.036 \%, 0.065 \%$ and $0.041 \%$ observed in the AN:TR (1:1), AN:TR (1:2), and AN:TR (2:1) co-culture respectively, falling further to $0.002 \%, 0.004 \%$ and $0.005 \%$ respectively after $168 \mathrm{~h}$. The AN:TR (1:1) co-culture resulted in the lowest residual lignin at the end of the pretreatment. It is probable that these fungi can degrade lignin because of their lignin-degrading enzymes, the two major ones contained in fungi being peroxidases and laccases (Pérez et al., 2002). T. reesei has been reported to be able to produce laccase (Adav \& Sze, 2014). In another previous study, A. niger was found to produce manganese peroxidase and lignin peroxidase (Asses et al., 2018). Moreover, A. niger is effective in caffeine degradation. Therefore, this co-culture ratio displayed good performance in lignin degradation, although there was the presence of caffeine as an inhibitor.

\subsubsection{Co-culture performance on pectin removal}

The pectin content in Figure $1 \mathrm{~b}$ shows a significant decrease, which was probably caused by the pectinase activity of the co-culture. The best co-cultures in pectin degradation were revealed to be BS:AN (2:1) and BS:TR (2:1), probably as the result of the greater addition of B. subtilis, a saprophytic bacterium, which is able to degrade the cell walls of plants using its pectinase enzyme. Some Bacillus sp., such as B. stearothermophilus, B. cereus and B. subtilis, have been reported to have very high pectinase activities with pectin as the substrate, with levels as high as 20-25 g/L of pectinase (Torimiro \& Okonji, 2013). B. subtilis strain 168 has been reported to display significant growth in plant cell wall polysaccharides such as pectin, polygalacturonan and rhamnogalacturonan type 1 (RG-1) as carbon sources (Ochiai et al., 2007). B. subtilis can produce large quantities of pectate lyase (acting on polygalacturonic acid), pectin lyase (acting on pectin), and polygalacturonate lyase (Gummadi \& Kumar, 2005).

Significant pectin removal was also detected in the A. niger and T. reesei co-culture. The initial pectin content of $2.28 \%$ dropped to $0.115 \%$ in the AN:TR (1:1) co-culture. In that of AN:TR (1:2), pectin decreased to $0.054 \%$, while for AN:TR (2:1) it decreased to $0.048 \%$. 
The degradation of lignocellulosic and pectin components by A. niger was inseparable from the role of extracellular enzymes with high activity, such as lipase, cellulase, amylase, hemicellulase and pectinase (Roda et al., 2014). According to Pandey et al. (2000), A. niger is the most suitable fungus for cultivation on coffee pulp and can produce pectinase. Seiboth et al. (2011) report that $A$. niger has at least 39 genes encoding enzymes, which are required for the degradation of the arabinan and arabinogalactan side chains in pectin. In contrast, T. reesei has only six pectinolytic enzymes for pectin degradation.

\subsection{Cellulose and Reducing Sugar Obtained after Pretreatment}

Based on a previous study, a greater decrease in lignin content could cause a greater increase in the cellulose fraction in CPW due to the destruction of lignin as a cellulose binder (Menon \& Rao, 2012).
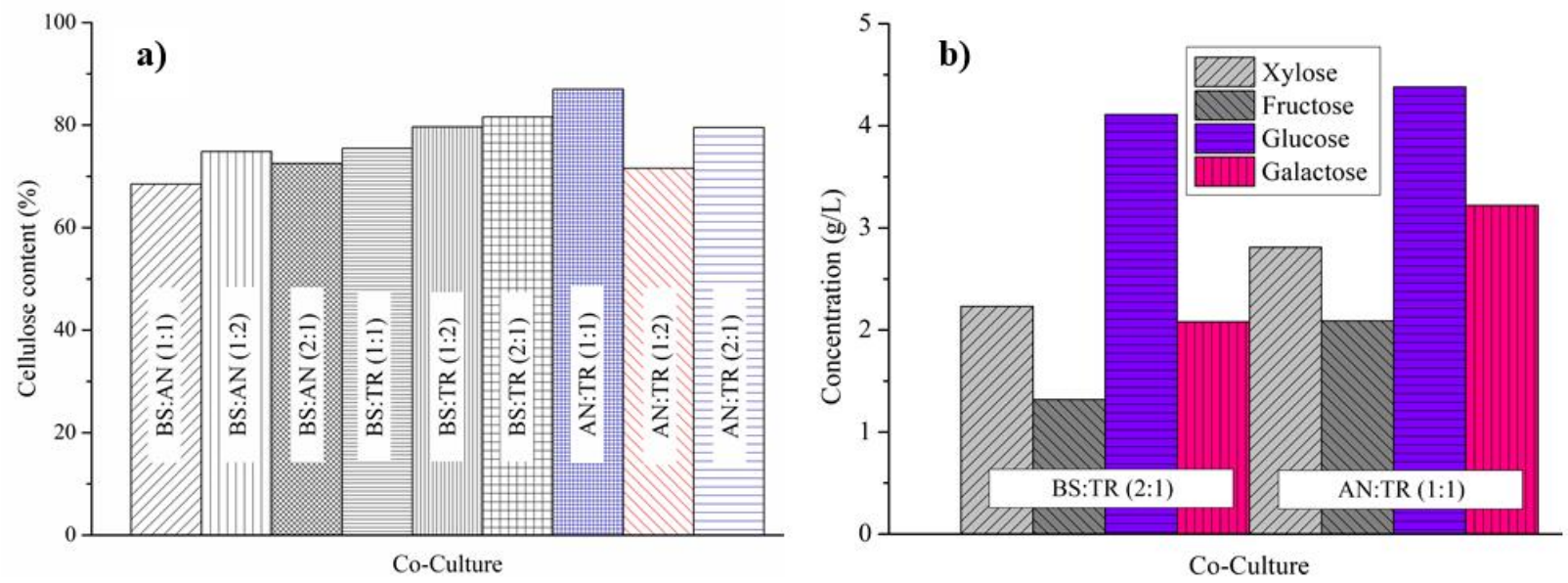

Figure 2 (a) Cellulose content in the pretreated CPW; (b) Reducing sugar concentration

Figure 2a shows the concentration of cellulose after seven days of the pretreatment process. The cellulose concentrations obtained in BS:AN with ratios of 1:1, 1:2 and 2:1 are 68.5\%,74.84\% and $72.52 \%(\mathrm{w} / \mathrm{w})$, respectively, while those in BS:TR with ratios of $1: 1,1: 2$, and $2: 1$ are $75.45 \%, 79.66 \%$, and $81.61 \%$ (w/w), respectively. In AN:TR with ratios of 1:1, 1:2 and 2:1, the cellulose concentrations are $86.99,71.57$, and $79.54 \%(\mathrm{w} / \mathrm{w})$, respectively. From the results, the BS:TR (2:1) and AN:TR (1:1) variables have cellulose concentrations over than $80 \%$ in recovered substrate, with increases in cellulose of $40.95 \%$ and $50.24 \%$ from the initial concentration respectively. These co-cultures were chosen for the following reducing sugar observation using $A$. niger and $T$. viride.

From Figure $2 b$, the concentrations of reducing sugar in the supernatant resulting from the pretreatment by BS:TR $(2: 1)$ and AN:TR $(1: 1)$ were $9.74 \mathrm{~g} / \mathrm{L}$ and $12.5 \mathrm{~g} / \mathrm{L}$, respectively. Subsequently, the reducing sugar obtained was analyzed using HPLC. Xylose, fructose, glucose and galactose components were detected, with glucose having the highest concentration in both the BS:TR (2:1) and AN:TR (1:1) co-cultures, at $4.11 \mathrm{~g} / \mathrm{L}$ and $4.38 \mathrm{~g} / \mathrm{L}$, respectively.

\subsection{Effect of Surfactant on CPW Hydrolysis by A. niger and T. viride Co-culture}

In this step, the pretreated $\mathrm{CPW}$ obtained was hydrolyzed using the co-culture of $A$. niger and T. viride, to which PEG 4000 had been added as a surfactant. PEG 4000 has been shown to produce around 7\% and 13\% higher amounts of reducing sugar than PEG 6000 and 8000, respectively, during the hydrolysis of $1 \mathrm{~g}$ of sugar beet shreds (Ivetić et al., 2014). Further hydrolysis was needed because the pretreated CPW still contained a considerable amount of cellulose, which can be converted into reducing sugars. These fungi were chosen due to their ability to degrade cellulose and hemicellulose into reducing sugar during the hydrolysis 
process. The combination of $A$. niger and $T$. viride was estimated to be able to maximize the degradation of CPW by their cellulase and xylanase enzyme (Goyal et al., 2008; Nathan et al., 2014; Roda et al., 2014). At the same time, T. viride also performed sinergistically with $A$. niger, producing the $\beta$-glucosidase enzyme in hydrolyzing cellobiose, which is an inhibitor of cellulase activity (Sun \& Cheng, 2002).

Table 2 Reducing sugar concentration and yield

\begin{tabular}{|c|c|c|c|c|}
\hline \multirow{2}{*}{$\begin{array}{c}\text { Pretreated } \\
\text { CPW }\end{array}$} & \multirow[b]{2}{*}{$\begin{array}{l}\text { Hydrolysis process } \\
\text { (ratio, v/v) }\end{array}$} & \multirow[b]{2}{*}{ Surfactant addition } & Result & \\
\hline & & & $\begin{array}{c}\text { Concentration of } \\
\text { reducing sugar }(\mathrm{g} / \mathrm{L})\end{array}$ & $\begin{array}{c}\text { Yield } \\
(\%)\end{array}$ \\
\hline \multirow{6}{*}{ BS:TR (2:1) } & AN:TV (1:1) & - & 11.26 & 11.63 \\
\hline & AN:TV (1:1) & $1 \mathrm{~g}$ of PEG 4000 & 11.92 & 12.31 \\
\hline & AN:TV (1:2) & - & 13.81 & 14.26 \\
\hline & AN:TV (1:2) & $1 \mathrm{~g}$ of PEG 4000 & 14.70 & 15.18 \\
\hline & AN:TV $(2: 1)$ & - & 12.64 & 13.05 \\
\hline & AN:TV (2:1) & $1 \mathrm{~g}$ of PEG 4000 & 13.53 & 13.97 \\
\hline \multirow{6}{*}{ AN:TR (1:1) } & AN:TV (1:1) & - & 16.20 & 16.73 \\
\hline & AN:TV $(1: 1)$ & $1 \mathrm{~g}$ of PEG 4000 & 18.90 & 19.51 \\
\hline & AN:TV (1:2) & - & 18.18 & 18.77 \\
\hline & AN:TV (1:2) & $1 \mathrm{~g}$ of PEG 4000 & 18.41 & 19.01 \\
\hline & AN:TV (2:1) & - & 16.76 & 17.30 \\
\hline & AN:TV (2:1) & $1 \mathrm{~g}$ of PEG 4000 & 20.04 & 20.69 \\
\hline
\end{tabular}

The reducing sugar obtained before the hydrolysis process was described in the previous section, in which the concentration resulting from the pretreatment process by BS:TR (2:1) was lower than that of AN:TR (1:1). After hydrolysis using AN:TV without surfactant, the reducing sugar concentration obtained was higher than that of the pretreatment, but still lower than that with the surfactant addition, as shown in Table 2. For the co-culture containing pretreated CPW using BS:TR (2:1) and without surfactant, the reducing sugar concentrations in co-cultures AN:TV (1:1), (1:2) and (2:1) were $11.26 \mathrm{~g} / \mathrm{L}, 13.81 \mathrm{~g} / \mathrm{L}$ and $12.64 \mathrm{~g} / \mathrm{L}$, respectively. These were respectively $15.61 \%, 41.79 \%$ and $29.77 \%$ higher than the pretreatment results. For the culture containing pretreated CPW by AN:TR (1:1), the concentrations of reducing sugar in cocultures AN:TV (1:1), (1:2) and (2:1) were $16.2 \mathrm{~g} / \mathrm{L}, 18.18 \mathrm{~g} / \mathrm{L}$ and $16.76 \mathrm{~g} / \mathrm{L}$, or $29.60 \%$, $45.44 \%$ and $34.08 \%$ higher than the results of the pretreatment, respectively.

To investigate the role of PEG 4000, the reducing sugar obtained from the culture with and without surfactant were compared, as shown in Table 2 . The reducing sugar concentration with the addition of surfactant resulted in a higher value than that without surfactant. The increases in reducing sugar concentrations in the co-culture containing pretreated CPW using BS:TR (2:1) and hydrolyzed by AN:TV (1:1), (1:2) and (2:1), with the addition of surfactant, were $5.86 \%, 6.44 \%$ and $7.04 \%$, figures which are higher than the results from the same co-culture without surfactant. In the co-culture containing pretreated CPW using AN:TR (1:1) and hydrolyzed by AN:TV (1:1), (1:2) and (2:1), the increases in reducing sugar concentration were respectively $16.67 \%, 1.27 \%$ and $19.57 \%$ compared to the results without the addition of surfactant. Furthermore, the effect of different ratios of AN to TV on the final result can also be evaluated. The co-culture with high $A$. niger composition tended to produce a higher reducing sugar concentration. This was probably because $A$. niger has all the essential components of a cellulase system, exo-glucanase, endo-glucanase and $\beta$-glucosidases, which can optimally convert cellulose to reducing sugar (Sohail et al., 2009). 
The yield of reducing sugar was calculated using Equation 1 and is shown in Table 2. At the end of the investigation period, the highest yield of reducing sugar from pretreated CPW using BS:TR (1:2) with the addition of PEG 4000 was obtained from AN:TV (1:2), with a value of $15.18 \%$, or $0.92 \%$ higher than without surfactant. The highest yield from pretreated CPW using AN:TR (1:1) with the addition of PEG 4000 was obtained from AN:TV (2:1), with a value of $20.69 \%$, or $3.4 \%$ higher than without surfactant. These results suggest that the addition of PEG 4000 in the pretreatment can achieve a higher concentration of reducing sugar than without such an addition, due to its role in absorbing and protecting the reducing sugar from denaturation during the hydrolysis process and in altering the structure of the substrate and increasing cellulose accessibility (Park et al., 2010). It has also been reported to have an effect on increasing enzyme activity during the hydrolysis process (Ferreira et al., 2009).

\section{CONCLUSION}

The microbial method in the form of a fungal and bacterial mixture has produced satisfying results in the degradation of lignin and pectin in coffee pulp waste, with more than $99 \%$ removal of those compounds. Due to the high cellulose concentration (more than $80 \%$ ) in pretreated coffee pulp waste, two co-cultures, AN:TR (1:1) and BS:TR (2:1), were chosen for the following hydrolysis process. Subsequently, the hydrolysis of pretreated CPW using $A$. niger and $T$. viride with the addition of surfactant resulted a higher yield of reducing sugar than that without surfactant. The highest yield of reducing sugar resulted from the pretreated CPW by AN:TR (1:1) and hydrolyzed by the AN:TV (2:1) co-culture with the addition of PEG 4000, at $20.69 \%$. In this co-culture, PEG 4000 as surfactant made a difference of $3.4 \%$ in reducing sugar, compared to without surfactant. Hopefully, the co-culture ratio obtained can indicate a direction for further study, focusing on the kinetics of its cell growth, which is important for developing an economical bioprocess of reducing sugar production.

\section{ACKNOWLEDGEMENT}

The authors thank Atikah Badriya Husein and Dwi Ayu Primaningrum who have provided coffee pulp waste and selfless help. We also thank all members of Biochemical Technology Laboratory and Wastewater Treatment Laboratory, Institut Teknologi Sepuluh Nopember for their endless support.

\section{REFERENCES}

Abbott, D.W., Boraston, A.B., 2008. Structural Biology of Pectin Degradation by Enterobacteriaceae. Microbiology and Molecular Biology Reviews, Volume 72(2), pp. 301316

Abd-Elsalam, H.E., El-Hanafy, A.A., 2009. Lignin Biodegradation with Ligninolytic Bacterial Strain and Comparison of Bacillus subtilis and Bacillus sp. Isolated from Egyptian Soil. Journal of Agriculture \& Environment Science, Volume 5(1), pp. 39-44

Adav, S.S., Sze, S.K., 2014. Trichoderma Secretome: An Overview. In: Biotechnology and Biology of Trichoderma, Gupta, V.K. Schmoll, M., Herrera-Estrella, A., Upadhyay, R.S., Druzhinina, I., Thouhy, M.G. Elsevier, pp. 103-114

Asses, N., Ayed, L., Hkiri, N., Hamdi, M., 2018. Congo Red Decolorization and Detoxification by Aspergillus niger: Removal Mechanisms and Dye Degradation Pathway. BioMed Research International, Volume 2018, pp. 1-9

Bandounas, L., Wierckx, N.J.P., de Winde, J.H., Ruijssenaars, H.J., 2011. Isolation and Characterization of Novel Bacterial Strains Exhibiting Ligninolytic Potential. BMC Biotechnology, Volume 11(94), pp. 1-11

Chang, Y.C., Choi, D.B., Takamizawa, K., Kikuchi, S., 2014. Isolation of Bacillus sp. Strains 
Capable of Decomposing Alkali Lignin and their Application in Combination with Lactic Acid Bacteria for Enhancing Cellulase Performance. Bioresource Technology, Volume 152, pp. 429-436

Cragg, S.M., Beckham, G.T., Bruce, N.C., Bugg, T.D.H., Distel, D.L., Dupree, P., Etxabe, A.G., 2015. Lignocellulose Degradation Mechanisms Across the Tree of Life. Current Opinion in Chemical Biology, Volume 29, pp. 108-119

Dussán, K.J., Silva, D.D.V., Moraes, E.J.C., Aruda P.V., Felipe, M.G.A., 2014. Dilute-acid Hydrolysis of Cellulose to Glucose from Sugarcane Bagasse. Chemical Engineering Transactions, Volume 38, pp. 433-438

Ferreira, S., Duarte, A.P., Ribeiro, M.H.L., Queiroz, J.A., Domingues, F.C., 2009. Response Surface Optimization of Enzymatic Hydrolysis of Cistus ladanifer and Cytisus striatus for Bioethanol Production. Biochemical Engineering Journal, Volume 45(3), pp. 192-200

Goyal, M., Kalra, K.L., Sareen, V.K., Soni, G., 2008. Xylanase Production with Xylan Rich Lignocellulosic Wastes by a Local Soil Isolate of Trichoderma viride. Brazilian Journal of Microbiology, Volume 39(3), pp. 535-541

Gummadi, S.N., Kumar, D.S., 2005. Microbial Pectic Transeliminases. Biotechnology Letters, Volume 27(7), pp. 451-458

Guo, P., Mochidzuki, K., Cheng, W., Zhou, M., Gao, H., Zheng, D., Wang, X., 2011. Effects of Different Pretreatment Strategies on Corn Stalk Acidogenic Fermentation using a Microbial Consortium. Bioresource Technology, Volume 102(16), pp. 7526-7531

Haryuni, Dewi, T.S.K., Suprapti, E., Rahman, S.F., Gozan, M., 2019. The Effect of Beauveria bassiana on The Effectiveness of Nicotiana tabacum Extract as Biopesticide Against Hypothenemus hampei to Robusta Coffee. International Journal of Technology, Volume 10(1), pp. 159-166

Ibrahim, S., Shukor, M.Y., Syed, M.A., Rahman, N.A.A., Khalil, K.A., Khalid, A., Ahmad, S.A., 2014. Bacterial Degradation of Caffeine: A Review. Asian Journal of Plant Biology, Volume 2(1), pp. 18-27

Ivetić, D.T., Šćiban, M.B., Antov, M.G., 2014. Enzymatic Hydrolysis of Pretreated Sugar Beet Shreds: Statistical Modeling of the Experimental Results. Biomass and Bioenergy, Volume 47, pp. 387-394

Juliastuti, S.R., Widjaja, T., Altway, A., Iswanto, T., 2017. Biogas Production from Pretreated Coffee-pulp Waste by Mixture of Cow Dung and Rumen Fluid in Co-digestion. In: AIP Conference Proceedings. Volume 1840(1)

Juliastuti, S.R., Widjaja, T., Altway, A., Sari, V.A., Arista, D., Iswanto, T., 2018. The Effects of Microorganism on Coffee Pulp Pretreatment as a Source of Biogas Production. In: MATEC Web of Conferences, Volume 156, pp. 1-7

Kumar, P., Barrett, D.M., Delwiche, M.J., Stroeve, P., 2009. Methods for Pretreatment of Lignocellulosic Biomass for Efficient Hydrolysis and Biofuel Production. Industrial and Engineering Chemistry Research, Volume 48(8), pp. 3713-3729

Kusrini, E., Wicaksono, W., Gunawan, C., Daud, N.Z.A., Usman, A., 2018. Kinetics, Mechanism, and Thermodynamics of Lanthanum Adsorption on Pectin Extracted from Durian Rind. Journal of Environmental Chemical Engineering, Volume 6(5), pp. 65806588

Li, J., Li, S., Fan, C., Yan, Z., 2012. The Mechanism of Poly(ethylene glycol) 4000 Effect on Enzymatic Hydrolysis of Lignocellulose. Colloids Surfaces B: Biointerfaces, Volume 89, pp. 203-210

Menezes, E.G.T., Carmo, J.R.C., Alves, J.G.L.F., Menezes, A.G.T., Guimarães, I.C., Queiroz, F., Pimenta, C.J., 2014. Optimization of Alkaline Pretreatment of Coffee Pulp for Production of Bioethanol. Biotechnology Progress, Volume 30(2), pp. 451-462

Menon, V., Rao, M., 2012. Trends in Bioconversion of Lignocellulose: Biofuels, Platform 
Chemicals \& Biorefinery Concept. Progress in Energy and Combustion Science, Volume 38(4), pp. 522-550

Mood, S.H., Golfeshan, A.H., Tabatabaei, M., Jouzani, G.S., Najafi, G.H., Gholami, Ardjmand, M., 2013. Lignocellulosic Biomass to Bioethanol, A Comprehensive Review with a Focus on Pretreatment. Renewable and Sustainable Energy Reviews, Volume 27, pp. 77-93

Nathan, V.K., Rani, M.E., Rathinasamy, G., Dhiraviam, K.N., Jayavel, S., 2014. Process Optimization and Production Kinetics for Cellulase Production by Trichoderma viride VKF3. SpringerPlus, Volume 3(92), pp. 1-12

Ochiai, A., Itoh, T., Kawamata, A., Hashimoto, W., Murata, K., 2007. Plant Cell Wall Degradation by Saprophytic Bacillus subtilis Strains: Gene Clusters Responsible for Rhamnogalacturonan Depolymerization. Applied and Environmental Microbiology, Volume 73(12), pp. 3803-3813

Pandey, A., Soccol, C.R., Nigam, P., Brand, D., Mohan, R., Roussos, S., 2000. Biotechnological Potential of Coff ee Pulp and Coff ee Husk for Bioprocesses. Biochemical Engineering Journal, Volume 6(2), pp. 153-162

Park, S., Baker, J.O., Himmel, M.E., Parilla, P.A., Johnson, D.K., 2010. Cellulose Crystallinity Index: Measurement Techniques and their Impact on Interpreting Cellulase Performance. Biotechnology for Biofuels, Volume 3(10), pp. 1-10

Ranganna, S., 1979. Manual of Analysis of Fruit and Vegetable Products. Tata McGraw-Hill Publ Co Ltd, New Delhi

Roda, A., De Faveri, D.M., Dordoni, R., Lambri, M., 2014. Vinegar Production from Pineapple Wastes - Preliminary Saccharification Trials. Chemical Engineering Transactions, Volume 37, pp. 607-612

Roussos, S., Aquiáhuatl, M.D.L.A, Trejo-Hernández, M.D.R, Perraud, I.G., Favela, E., Ramakrishna, M., Raimbault, M., Viniegra-Gonzalez, G., 1995. Biotechnological Management of Coffee Pulp - Isolation, Screening, Characterization, Selection of Caffeinedegrading Fungi and Natural Microflora Present in Coffee Pulp and Husk. Applied Microbiology and Biotechnology, Volume 42(5), pp. 756-762

Seiboth, B., Ivanova, C., Seiboth, V.S., 2011. Trichoderma reesei: A Fungal Enzyme Producer for Cellulosic Biofuels. In: Biofuel Production-Recent Developments and Prospects, Vienna University of Technology, Austria, pp. 309-340

Sohail, M., Siddiqi, R., Ahmad, A., Khan, S.A., 2009. Cellulase Production from Aspergillus niger MS82: Effect of Temperature and pH. New Biotechnology, Volume 25(6), pp. 437 441

Sun, Y., Cheng, J., 2002. Hydrolysis of Lignocellulosic Materials for Ethanol Production: A Review. Bioresource Technology, Volume 83(1), pp. 1-11

Torimiro, N., Okonji, E.R., 2013. A Comparative Study of Pectinolytic Enzyme Production by Bacillus Species. African Journal of Biotechnology, Volume 12(46), pp. 6498-6503

Widjaja, T., Iswanto, T., Altway, A., Shovitri, M., Juliastuti, S.R., 2017a. Methane Production from Coffee Pulp by Microorganism of Rumen Fluid and Cow Dung in Co-digestion. Chemical Engineering Transactions, Volume 56, pp. 1465-1470

Widjaja, T., Iswanto, T., Agustiani, E., Altway, A., Silaban, B.M.J., Yuwono, L.F., $2017 b$. Optimization of Palmyra Palmsap Fermentation using Co-culture of Saccharomyces cerevisiae and Pichia stipitis. ARPN Journal of Engineering and Applied Sciences, Volume 12(23), pp. 6817-6824 